\title{
Preparation of Copoly(styrene/butyl methacrylate) Beads and Composite Particles containing Carbon Black with Hydrophobic Silica as a Stabilizer in Aqueous Solution
}

\author{
Kyungho Chung and Moonsoo Park ${ }^{\dagger}$ \\ Department of Polymer Engineering, University of Suwon \\ San 2-2, Wawuri, Bongdameup, Hwasung, Gyeonggido, Korea 445-743 \\ (Received December 26, 2011, Revised February 20, 2012, February 27, Accepted February 29, 2011)

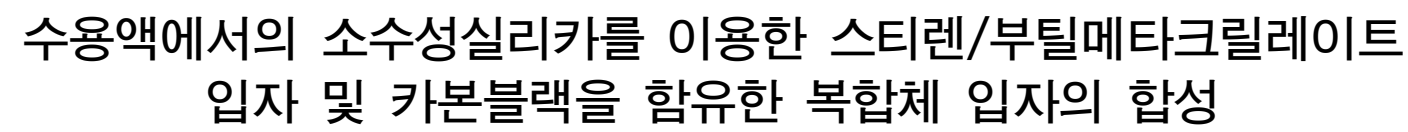

\author{
정경호. 박문수 ${ }^{\dagger}$ \\ 수원대학교 신소재공학과 \\ 접수일(2011년 12월 26일), 수정일(1차: 2012년 2월 20일, 2차:2월 27일), 게재확정일(2012년 2월 29일)
}

\begin{abstract}
A suspension copolymerization of styrene and butyl methacrylate (BMA) in the aqueous phase was conducted at a selected temperature between 65 and $95{ }^{\circ} \mathrm{C}$. Hydrophobic silica was selected as a stabilizer and azobisisobutyronitrile (AIBN) as an initiator. Optimum dispersion of silica in water was obtained at $\mathrm{pH} 10$ while polymerization reaction was run at $\mathrm{pH}$ 7. TGA and EDS measurements revealed that $90 \%$ of silica functioned as a stabilizer and $10 \%$ were incorporated into polymeric particles. Average particle diameter decreased with increasing amounts of stabilizer. Molecular weights displayed an increase when the stabilizer concentration reached $1.67 \mathrm{wt} \%$. An increase in the initiator concentration and/or reaction temperature raised the reaction rate but decreased molecular weights. Particle diameter was nearly independent of the initiator concentration and reaction temperature. An increase in the BMA proportion decreased the glass transition temperature and increased the particle diameter with irregularity in shape. Incorporation of carbon black into the particles composed of styrene and BMA prolonged the reaction time before reaching completion. We have confirmed that a suspension copolymerization of styrene and BMA with hydrophobic silica as a stabilizer can produce spherical composite particles with $1-30 \mu \mathrm{m}$ in diameter containing carbon black.
\end{abstract}

요 약 : 물을 반응매체로 하고 스티렌과 부틸메타크릴레이트 (BMA)를 단량체로 하여 $65^{\circ} \mathrm{C}$ 에서 $95^{\circ} \mathrm{C}$ 사이의 선택된 온도에서 현탁중합을 실시하였다. 소수성 실리카를 안정제로, azobisisobutyronirile (AIBN)을 개시제로 선택하였다. 안정제의 최적 분산은 $\mathrm{pH}$ 10에서 이루어졌으며 반응은 $\mathrm{pH}$ 7에서 진행하였다. TGA 및 $\mathrm{EDS}$ 측정으로 사용한 실리카 의 $90 \%$ 는 안정제로 $10 \%$ 는 입자 내로 유입되는 것으로 분석되었다. 안정제의 농도가 증가할수록 평균입경은 감소하 였다. 분자량은 안정제의 농도가 $1.67 \mathrm{wt} \%$ 에 이르며 증가하였다. 개시제의 농도 및/혹은 반응온도의 상승에 따라 반응속도는 증가하였으나 분자량은 감소하였다. 입자의 입경은 개시제의 농도 및 반응온도에 거의 무관하였다. BMA 의 비가 증가하면서 유리전이온도는 감소하였으며 불규칙한 형상의 입자가 증가하였다. 카본블랙을 함유하는 스티렌 /BMA의 중합반응은 반응완료에 보다 많은 시간이 소요되었다. 소수성 실리카를 안정제로 하는 현탁중합반응을 이용 하여 카본블랙을 함유하는 평균입경이 1-30 $\mu \mathrm{m}$ 의 구형 폴리(스티렌-BMA) 공중합체 복합체 입자를 합성할 수 있다는 사실을 확인하였다.

Keywords : suspension copolymerization, hydrophobic silica, stabilizer, carbon black, polymer composite particles

\section{I . Introduction}

Applications of monodisperse polymeric particles are reaching various scientific fields, such as photonic band crystals, ${ }^{1}$ lithographic photo masks, ${ }^{2}$ drug delivery systems, ${ }^{3}$ size ex-

${ }^{\dagger}$ Corresponding Author. E-mail: amparks@suwon.ac.kr clusion chromatography ${ }^{4}$ and adhesives. ${ }^{5}$ Synthesizing techniques to prepare these particles include emulsion polymerization, soap-free emulsion polymerization and suspension polymerization. The formation of stable aqueous solution depends not only on the wettability and initial placement of polymeric particles but on the interaction between individual particles. Strong hydrophilic stabilizers are usually present in 
the aqueous phase, and as a result, they do not provide adequate repulsive power to prevent aggregation of particles. On the other hand, strong hydrophobic stabilizers are placed in the oil phase, reducing the stability of particles in water. Accordingly, the degree of wettability of stabilizers determines the stability of the aqueous solution containing polymeric particles.

Emulsion polymerization usually generates submicron particles whose diameters are in the order of nanometers. To overcome these limitations in diameter Omi et al. ${ }^{6}$ employed counterion monomers and initiator in seed emulsion polymerization and obtained particles close to $1 \mu \mathrm{m}$ in diameter. Noda et $\mathrm{al}^{7}{ }^{7}$ increased particle diameters to $2 \mu \mathrm{m}$ with a nonionic surfactant and a small amount of sodium chloride as a catalyst by emulsion polymerization. Kim et al. ${ }^{8}$ synthesized polystyrene composite particles in the range of 75 to $950 \mathrm{~nm}$ in diameter containing metal stearates by emulsion polymerization. Despite these improvements, emulsion polymerization is more widely used to prepare nano-sized polymeric beads less than $1 \mu \mathrm{m}$ in diameter., ${ }^{9,10}$

On the other hand, studies have been conducted on preparing polymeric beads with diameters ranging between 0.1 and 10 $\mu \mathrm{m}$ by soap-free emulsion polymerization. Since emulsifiers are not used in soap-free emulsion polymerization, it produces particles without emulsifier on the bead surface. In soap-free emulsion polymerization, ionic surfactants forming at the beginning of the reaction function as emulsifiers, enabling simultaneous creation of nucleation, and thus resulting in monodisperse particles. ${ }^{11-15}$ However, soap-free emulsion polymerization shows limitations in that the stability of the emulsion is highly dependent on the concentration and solubility of monomer and initiator in the water phase. Furthermore, depending on the monomer, particles form only when the concentration of monomer relative to water becomes less than $10 \%$ and particle size distribution no longer exhibits monodispersity when particle diameter exceeds $1 \mu \mathrm{m}^{16}$

In a suspension polymerization, Olayo et al. ${ }^{17}$ reported that an increase in the molecular weight of the organic stabilizer of poly(vinylalcohol) reduced the surface tension of polystyrene particles, resulting in a decrease in particle diameter from $500 \mu \mathrm{m}$ to $20 \mu \mathrm{m}$. On the other hand, there are inorganic stabilizers such as phosphates, sulfates, carbonates and hydroxides. ${ }^{18}$ Taguchi et al. ${ }^{19}$ prepared various shapes of calcium carbonates at different temperatures and used these stabilizers in a suspension polymerization of styrene. Calcium carbonates were found to be rectangular when prepared at 20 ${ }^{\circ} \mathrm{C}$, and dendritic when prepared at $70^{\circ} \mathrm{C}$. Polystyrene beads displayed an average diameter of $1.5 \mathrm{~mm}$ after 8 hours of reaction with the former and $400 \mu \mathrm{m}$ with the latter. Murakami et al. ${ }^{20}$ reported that hydrophilic poly(vinyl acetate) particles with 1-10 $\mu \mathrm{m}$ in diameter could be synthesized with a stabilizer composed of PVA, borate, and calcium carbonate by controlling the concentration of borate. Shaghaghi and Mahdavian ${ }^{21}$ investigated the effect of a stabilizer system composed of tricalciumphosphate and sodium dodecylbenzene sulfonate in a suspension polymerization of styrene and found that average particle diameter varied from 74 to $600 \mu \mathrm{m}$. Abu-Ayana and Mohsen ${ }^{22}$ derived new empirical equations correlating the average particle diameter and particle size distribution in the range of 224 to $1240 \mu \mathrm{m}$ in a suspension polymerization of methyl methacrylate with starch as a stabilizer and benzoyl peroxide as an initiator. Kim. et al. ${ }^{23}$ reduced the diameter of polystyrene particles to $40 \mu \mathrm{m}$ containing montmorillonite. Sawatari et al. ${ }^{24}$ homogenized a mixture of styrene-butyl acrylate monomers and magnetic particles, successfully preparing 5-8 $\mu \mathrm{m}$ composite particles by suspension polymerization.

We reported that polystyrene and poly(butyl methacrylate) particles in the range of 1-30 $\mu \mathrm{m}$ can be prepared with hydrophobic silica. ${ }^{25,26}$ We made surface modification by carefully controlling the $\mathrm{pH}$ of solution. We speculate that careful control of acidity imparts necessary hydrophilicity to hydrophobic silica particles by changing the chemical structure of the surface of silica particles. Based on these observations, we made an attempt to synthesize copolymer particles composed of styrene and butyl methacrylate by suspension polymerization with hydrophobic silica as a stabilizer and water as a reaction medium.

\section{Experimental}

\section{Materials}

The styrene and butyl methacrylate monomers and AIBN initiator are the products of Junsei Chemical. The hydrophobic silica, Aerosil R972, is a product of Degussa. The carbon black MA77 was purchased from Mitsubishi Chemical with its diameter $23 \mathrm{~nm}$ and BET surface area of $130 \mathrm{~m}^{2} / \mathrm{g}$. The water used for polymerization is deionized water from Jeil Distillator. The methanol is an analytical reagent grade from Daejung Chemical and nitrogen is obtained from Sugi Gas Company.

\section{Polymerization}

Prior to polymerization, phenolic inhibitors in the styrene and butyl methacrylate monomers were removed by washing three times with a $10 \%$ sodium hydroxide solution and then three times with deionized water. The AIBN was dissolved into methanol, filtered, vacuum-dried, and then used for polymerization reaction

For the dispersion of silica particles, a selected amount of ammonium hydroxide solution was added to $450 \mathrm{ml}$ of water 
to adjust it to $\mathrm{pH} 10$. Hydrophobic silica was then added to the solution and homogenized at 5,000 rpm for 10 minutes. After confirming that silica particles were dispersed in water, $\mathrm{pH}$ was adjusted to 7 with formic acid for polymerization. Finally, $150 \mathrm{ml}$ of the styrene and butyl methacrylate with the selected ratio between the two monomers containing the initiator was added to this solution and homogenized at 5000 rpm for 10 minutes to form preliminary particles in water at the room temperature.

The polymerization reaction was carried out at a selected temperature between 65 and $95{ }^{\circ} \mathrm{C}$ in a 1-liter kettle reactor with internal stirring. The reactor was immersed in a thermostated water bath to maintain a constant temperature. A water-cooled condenser, which was connected to the atmosphere via a wash-bottle containing water, was fixed to the reactor to prevent back-diffusion of oxygen into the reacting system. Nitrogen was bubbled through a thin Teflon tube into the reactor. The stirring speed was maintained at $300 \mathrm{rpm}$ with a digital controller. The reaction was sustained for several hours, depending on reaction temperature, initiator, stabilizer and monomer concentrations. At selected intervals, aliquots were removed from the reactor and conversion and bead size were determined. Solid beads were separated from the latex and washed with a $5 \%$ hydrofluoric solution and water three times to remove stabilizer. Beads were then dried in a vacuum oven at $50{ }^{\circ} \mathrm{C}$ for 48 hours.

\section{Characterization}

\subsection{Scanning Electron Microscopy (SEM).}

A Jeol, Model JSM-5600, scanning electron microscope was employed for polymeric particle size studies. One drop of filtered latex sample was placed on an aluminum sample holder, dried at room temperature, and sputtered-coated with gold and palladium for 3 minutes.

\subsection{Optical Microscopy (OM).}

A Nikon, Labophoto-2, optical microscope was used for particle size studies. One drop of filtered latex sample was placed on a microcover glass slide. The image was conveyed to the computer screen via an $\mathrm{A} / \mathrm{D}$ converter.

\subsection{Laser Particle Size Analyzer (PLSA).}

A Malvern Mastersizer 2000 was selected to measure particle diameter and particle size distribution. One drop of suspension was injected into the pump and analyzed by the computer.

\subsection{Gel Permeation Chromatography (GPC).}

The molecular weight of unfilled copoly(styrene/BMA) beads was determined by gel permeation chromatography
(Waters Breeze System) using calibration curves with polystyrene standards. The copolymer particles were dissolved in tetrahydrofuran (THF) and its concentration was maintained at 0.1 wt $\%$.

\subsection{Differential Scanning Calorimetry (DSC)}

Glass transition temperatures were determined with a differential scanning calorimeter (DSC-Pyris 6) and repeatedly calibrated with indium standards for maximum accuracy. Samples were heated to $200{ }^{\circ} \mathrm{C}$ for 2 minutes and quenched to $0{ }^{\circ} \mathrm{C}$. After 5 minutes, they were heated at $10{ }^{\circ} \mathrm{C} / \mathrm{min}$ to $200{ }^{\circ} \mathrm{C}$. $\mathrm{Tg}$ was identified as the midpoint of the endothermic displacement between linear baselines.

\section{Results and Discussion}

We carried out a suspension polymerization reaction in a 1 -liter kettle reactor in water. We selected the hydrophobic silica $\mathrm{R} 972$ as a stabilizer for the polymerization reaction. R972 has a structure of $\mathrm{Si}\left(\mathrm{CH}_{3}\right)_{2} \mathrm{Cl}_{2}$ with $16 \mathrm{~nm}$ in diameter $\left(130 \mathrm{~m}^{2} / \mathrm{g}\right)$ and $0.05 \mathrm{~g} / \mathrm{cm}^{3}$ in density. ${ }^{27}$ It is reported that silica particles show an increase in water solubility when $\mathrm{pH}$ approaches alkalinity. ${ }^{28}$ Accordingly, we investigated the extent of solubility by increasing $\mathrm{pH}$ with ammonium solution and found that solubility exhibited a large increase at around $\mathrm{pH} 10$. We speculate that a substitution reaction is taking place between ammonium solution and silica, and as a result, the chloride ion is replaced by the hydroxide ion. These hydroxide ions form hydrogen bonding with the water, which contributes to a large increase in the solubility of silica particles in water. When polymerization reaction was carried out at $\mathrm{pH} 10$, however, the results demonstrated a poor reproducibility, which often led to coagulation. In order to find the optimum reaction condition, we varied reaction acidity from $\mathrm{pH} 10$ to $\mathrm{pH} 7$ by adding a few drops of formic acid and found that reaction displayed the highest reproducibility at $\mathrm{pH}$ 7. Combined effects of a balance between hydrophobicity and hydrophilicity and an electrostatic balance among the chloride, hydroxide and carboxylate ions, as well, may have led to this phenomenon. Based on these observations, we employed $\mathrm{pH} 7$ for all polymerization reactions.

We used $150 \mathrm{ml}$ of monomer and $450 \mathrm{ml}$ of water for all reactions. The initiator concentration was fixed to be $1.0 \mathrm{wt} \%$ $(1.5 \mathrm{~g})$ relative to $150 \mathrm{ml}$ of water. Before the polymerization reaction, we used a homogenizer to create preliminary particles (preparticles) at the room temperature in the water phase. We selected the ratio between styrene and BMA at $7 / 3$ and varied the stabilizer concentration from $0.67 \mathrm{wt} \%(3.0 \mathrm{~g})$ to $3.33 \mathrm{wt} \%(15.0 \mathrm{~g})$ relative to the water. When we increase the stabilizer concentration in a suspension polymerization, the viscosity of suspension increases, enhancing dispersion and re- 
ducing surface tension, and as a result, particle size decreases. Figure 1 shows the variation of preliminary particles (preparticles) in shape and diameter at the room temperature depending on the stabilizer concentration as observed by optical microscopy. As shown here, relatively large preparticles with irregularity form when the silica concentration was $0.67 \mathrm{wt} \%$ (SB01, Figure 1(a)) relative to the water. As the silica concentration increases to $1.00 \mathrm{wt} \%$ (SB02, Figure 1(b)), particle diameter exhibits a noticeable decrease and smaller particles begin to form with less coagulation. When the silica concentration reaches $1.67 \mathrm{wt} \%$ (SB03, Figure 1(c)), coagulation nearly disappears and particles appear to be apart from each other compared to SB02. With further increase in stabilizer concentration to $3.33 \mathrm{wt} \%$ (SB04), particles become smaller with nearly no coagulation, as seen in Figure 1(d). On the other hand, an increase in the amount of stabilizer will not affect the ratio between the monomer and initiator inside polymeric particles, and as a result, reaction conversion against reaction time will remain independent of stabilizer con- centration. We found that stabilizer concentration had no impact on reaction conversion, in accordance with what we reported in the previous papers. ${ }^{25,26}$

We found that polymerization reaction reached completion 6 hours after the onset of the polymerization reaction regardless of the stabilizer concentration. When the polymerization reaction was over, we cleaned the entire suspension with 5\% hydrogen fluoride (HF) solution to remove silica particles for thermal, visual and molecular weight measurement. Figure 2 displays SEM photos of PBMA particles (SB16) before (Fig. 2(a)) and after cleaning (Fig. 2(b)) with 5\% HF solution. As can be seen here, PBMA particles show a distinctively clear surface after cleaning. In order to make a quantitative analysis on the degree of cleaning, we ran TGA and EDS with PBMA particles. Figure 3 shows the results of TGA measurement. As can be seen here, PBMA particles before cleaning with $5 \% \mathrm{HF}$ solution contains $0.998 \mathrm{wt} \%$ at $560^{\circ} \mathrm{C}$, in good agreement with the $1.0 \mathrm{wt} \%$ that we selected for the stabilizer concentration. On the other hand, PBMA particles

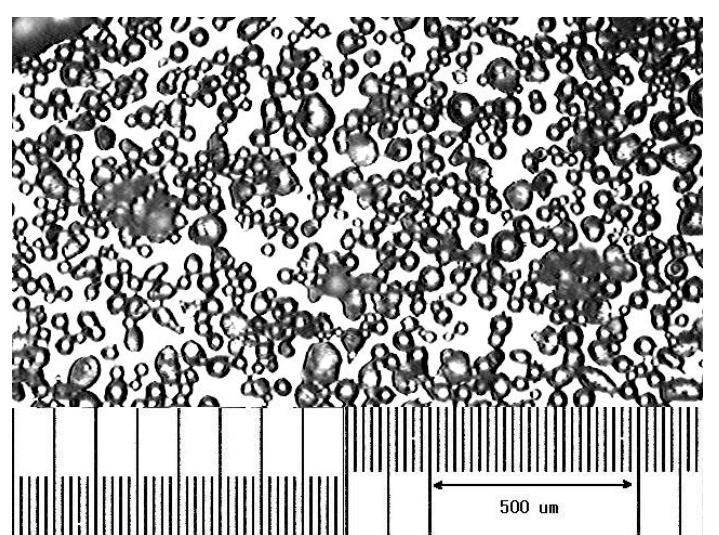

(a)

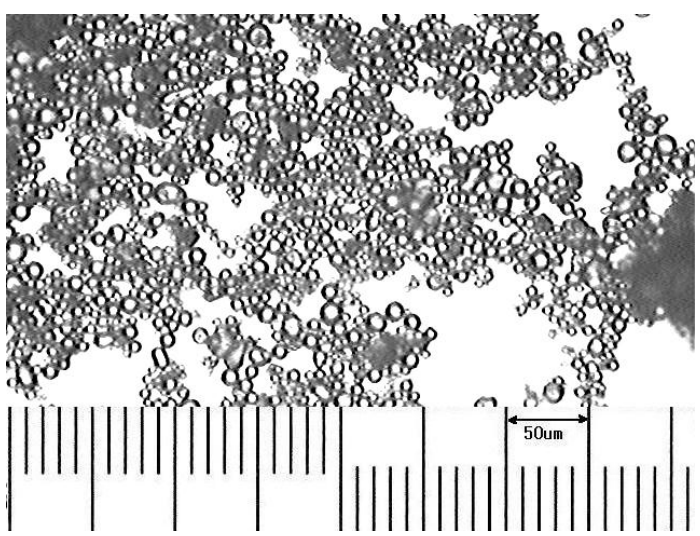

(c)

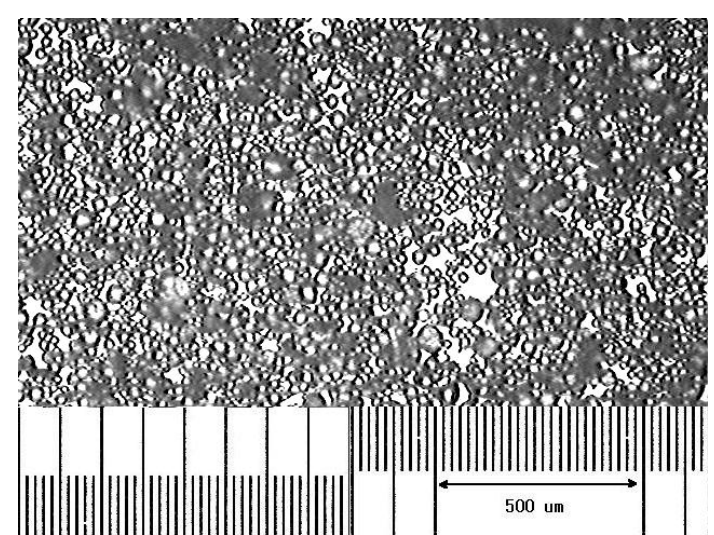

(b)

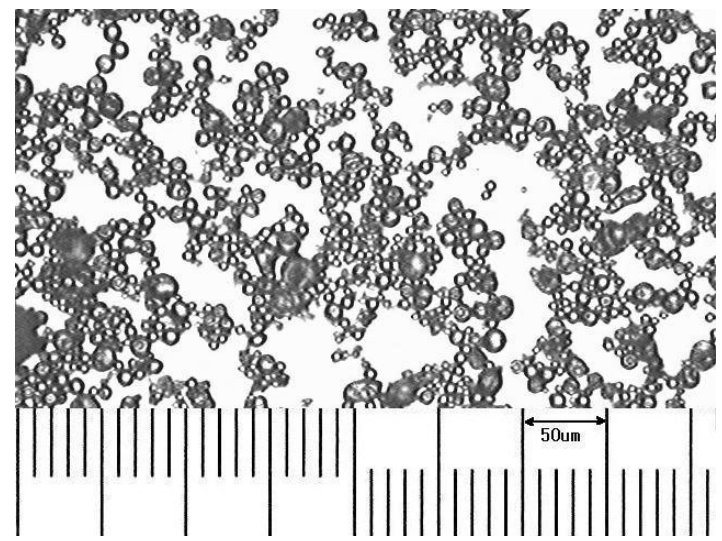

(d)

Figure 1. Optical microscopic photographs of varying preliminary particles composed of styrene and BMA with the ratio of 7/3 as a function of silica concentration: (a) $0.67 \mathrm{wt} \%$ (SB01, X200), (b) $1.00 \mathrm{wt} \%$ (SB02, X400), (c) $1.67 \mathrm{wt} \%$ (SB03, X400), (d) 3.33 wt\% (SB04, X400). 
after cleaning with 5\% HF solution contain $0.268 \mathrm{wt} \%$. Since $0.268 \mathrm{wt} \%$ represents the amount of silica both on the particle surface and that inside of PBMA particles, if any, we made an observation of the inner morphology of PBMA particles by TEM. As can be seen in Figure 4, TEM photos of PBMA particles after cleaning with $5 \% \mathrm{HF}$ solution display the presence of silica particles inside of PBMA particles. There are silica particles in both small and large particles $(0.5 \mu \mathrm{m}$ in diameter, Figure 4(a) and $0.2-0.4 \mu \mathrm{m}$ in diameter, Figure 4(b)). These silica particles are speculated to retain hydrophobicity even after the surface modification, and as a result, are incorporated into PBMA particles. Due to electric beams of $400 \mathrm{KV}$, the surfaces of PBMA particles melted and the boundary line became distorted. To figure out the amount of silica remaining on the surface of PBMA particles, we employed EDS on PBMA particles and found that the amount of silica was $0.17 \mathrm{wt} \%$. The difference between $0.268 \mathrm{wt} \%$ (from TGA measurement) and $0.17 \mathrm{wt} \%$ (from EDS measure-

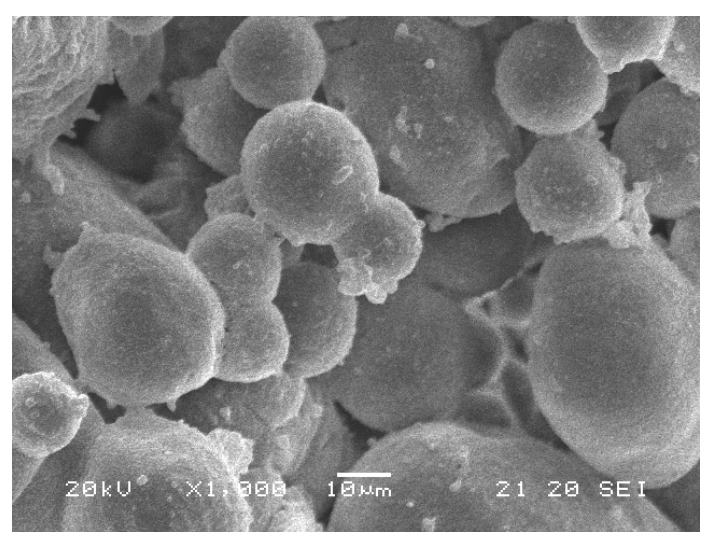

(a)

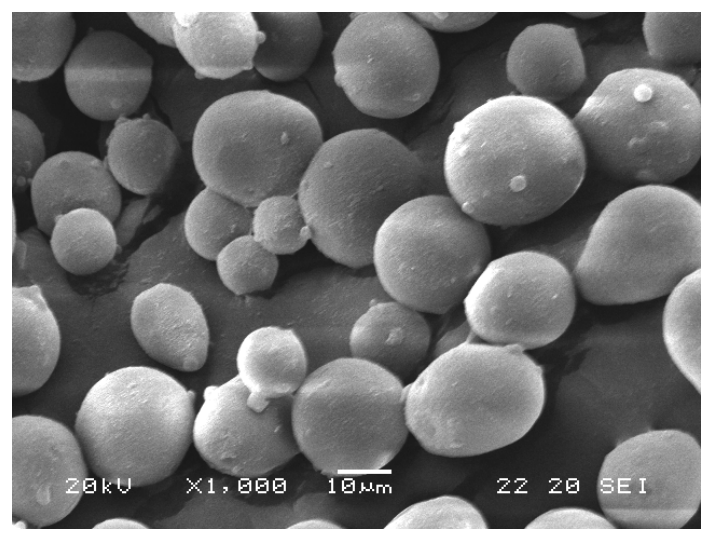

(b)

Figure 2. SEM photographs of poly(butyl methacrylate) particles (SB16) after suspension polymerization for $6 \mathrm{~h}$ with 1.0 $\mathrm{wt} \%$ hydrophobic silica as a stabilizer and $1.0 \mathrm{wt} \% \mathrm{AIBN}$ as an initiator at $75{ }^{\circ} \mathrm{C}(\times 1,000)$ : (a) PBMA particles before cleaning and (b) PBMA particles after cleaning with $5 \mathrm{wt} \% \mathrm{HF}$ solution.

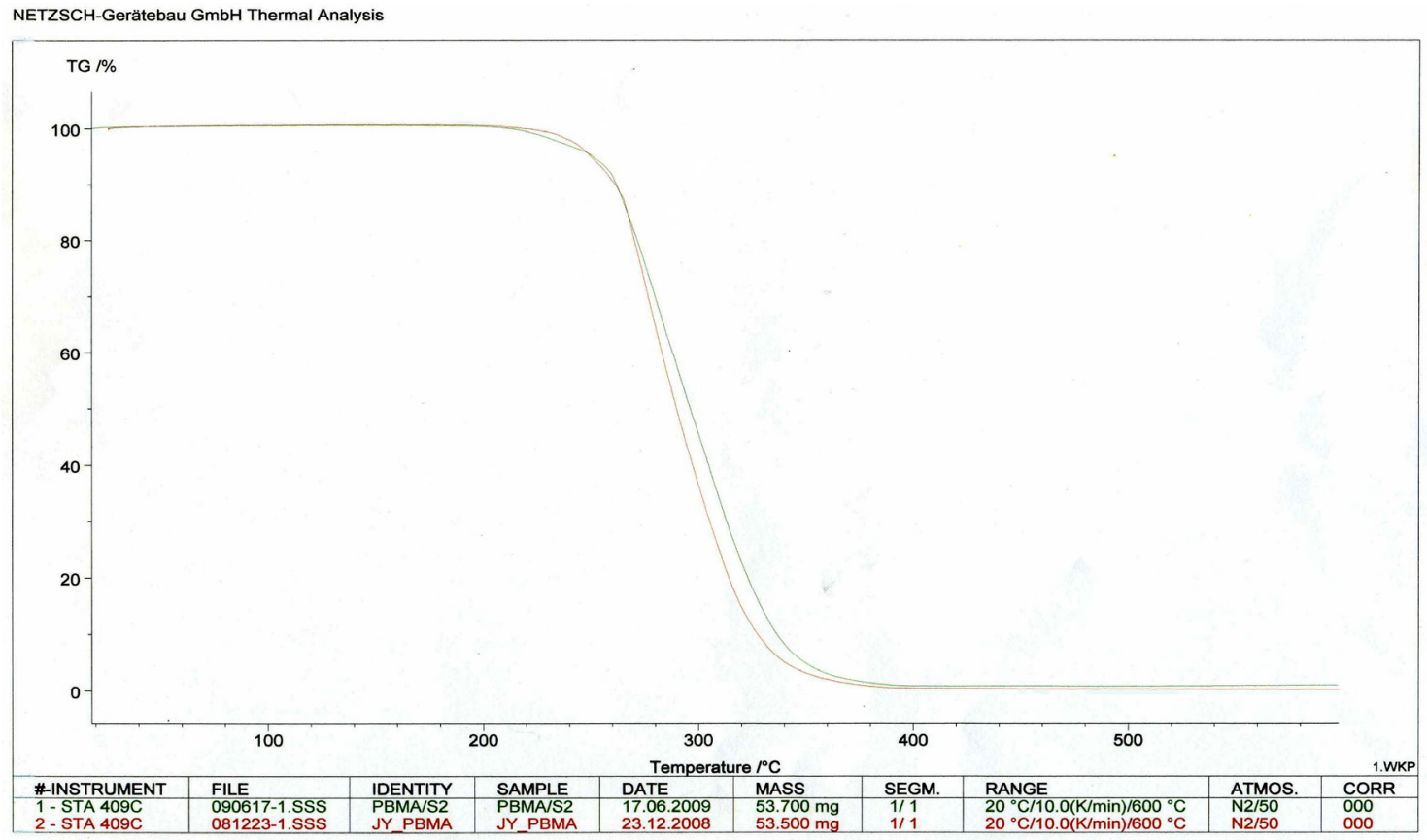

Figure 3. TGA measurement of PBMA particles (SB16) (a) before cleaning (0.998\%, top line) and (b) after cleaning with $5 \mathrm{wt} \% \mathrm{HF}$ solution $(0.268 \%$, bottom line). 
ment) is $0.098 \mathrm{wt} \%$, which is the amount of silica particles absorbed into and, as a result, residing inside of PBMA particles.

Measurement of copolymer particle diameters with a Malvern laser particle size analyzer, after the polymerization reaction and cleaning with $5 \% \mathrm{HF}$ solution, displayed average particle diameters of $42.1 \mu \mathrm{m}$ (SB01), $18.3 \mu \mathrm{m}$ (SB02), 14.3 $\mu \mathrm{m}$ (SB03) and $8.23 \mu \mathrm{m}$ (SB04). These particle diameters are observed to be in close proximity to the preliminary particle diameters as shown in Figure 1. Though an increase in the stabilizer concentration reduces particle size, in general, it will not impact the molecular weight since the concentration of the initiator relative to the monomer remains the same in each preliminary particle. As seen in Table 1, both the number

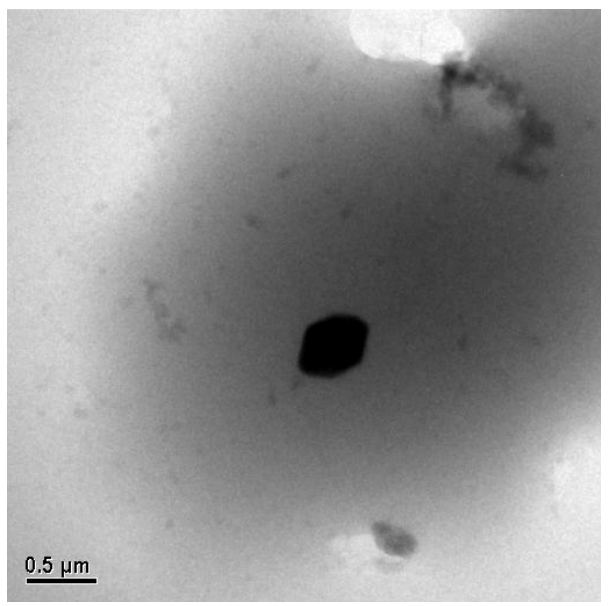

(a)

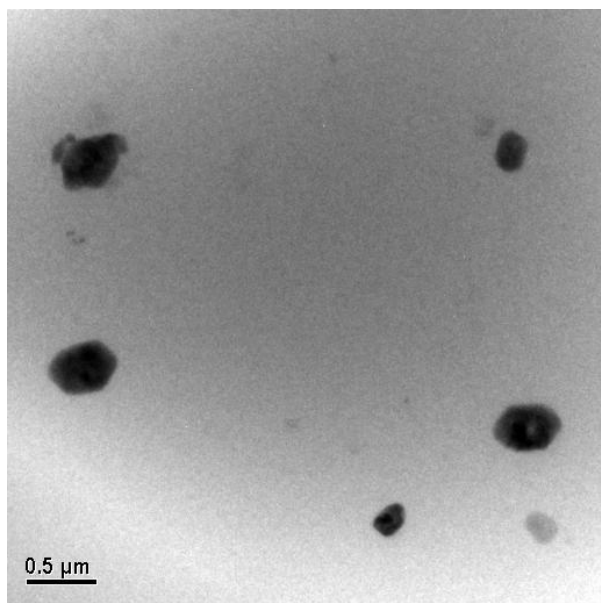

(b)

Figure 4. TEM images of PBMA particles (SB16) prepared by suspension polymerization for $6 \mathrm{~h}$ with $1.0 \mathrm{wt} \%$ hydrophobic silica as a stabilizer and $1.0 \mathrm{wt} \%$ AIBN as an initiator at $75{ }^{\circ} \mathrm{C}$ after washing with $5 \% \mathrm{HF}$ solution: (a) a small particle, (b) a large particle.
Table 1. Effect of Stabilizer Concentration on the Molecular Weights of Copoly (styrene/BMA) particles with the ratio of $7 / 3$ prepared at $75{ }^{\circ} \mathrm{C}$ with $1.0 \mathrm{wt} \% \mathrm{AIBN}$ as an Initiator by Suspension Polymerization

\begin{tabular}{c|c|c|c|c}
\hline ID & silica $(\mathrm{g})$ & silica $(\mathrm{wt} \%)$ & $\mathrm{Mn}(\mathrm{g} / \mathrm{mol})$ & $\mathrm{Mw}(\mathrm{g} / \mathrm{mol})$ \\
\hline SB01 & 3.0 & 0.67 & 49,700 & 142,900 \\
\hline SB02 & 4.5 & 1.00 & 44,800 & 136,800 \\
\hline SB03 & 7.5 & 1.67 & 54,800 & 184,700 \\
\hline SB04 & 15 & 3.33 & 51,300 & 167,000 \\
\hline
\end{tabular}

Table 2. Variation of the Molecular Weights and Glass Transition Temperature of Copoly(styrene/BMA) Particles as a function of the ratio between the two monomers prepared at $75{ }^{\circ} \mathrm{C}$ with $1.0 \mathrm{wt} \%$ silica as a Stabilizer and $1.0 \mathrm{wt} \% \mathrm{AIBN}$ as an Initiator by Suspension Polymerization

\begin{tabular}{c|c|c|c|c|c}
\hline ID & Styrene & BMA & $\mathrm{Mn}(\mathrm{g} / \mathrm{mol})$ & $\mathrm{Mw}(\mathrm{g} / \mathrm{mol})$ & $\mathrm{Tg}\left({ }^{\circ} \mathrm{C}\right)$ \\
\hline SB11 & 10 & 0 & 52,300 & 190,300 & 97.3 \\
\hline SB12 & 9 & 1 & 47,600 & 161,700 & 88.7 \\
\hline SB02 & 7 & 3 & 44,800 & 136,800 & 72.6 \\
\hline SB13 & 5 & 5 & 41,000 & 144,800 & 50.1 \\
\hline SB14 & 3 & 7 & 63,800 & 133,400 & 39.0 \\
\hline SB15 & 1 & 9 & 86,900 & 177,100 & 32.3 \\
\hline SB16 & 0 & 10 & 117,900 & 331,800 & 24.7 \\
\hline
\end{tabular}

and weight average molecular weights of copolymer particles after the polymerization reaction for 6 hours are close to one another below $1.0 \mathrm{wt} \%$ stabilizer concentration (SB01 and SB02). On the other hand, when the stabilizer concentration reaches $1.67 \mathrm{wt} \%(\mathrm{SB} 03)$ and $3.33 \mathrm{wt} \%(\mathrm{SB} 04)$ relative to the water, both the number and weight average molecular weights display a noticeable increase. An excessive amount of stabilizer beyond $1.67 \mathrm{wt} \%$ may reduce the actual concentration of the initiator in the polymerization reaction, and as a result, contributing to an increase in molecular weights. We observed similar phenomena in a suspension polymerization of styrene ${ }^{25}$ and that of butyl methacrylate ${ }^{26}$ with hydrophobic silica as a stabilizer.

Table 2 shows the variation of the molecular weights of copolymer particles as a function of the ratio between the styrene and BMA monomer. We conducted a suspension copolymerization at $75^{\circ} \mathrm{C}$ for 6 hours with the initiator concentration fixed at $1.0 \mathrm{wt} \%$ relative to the monomer and the stabilizer concentration at $1.0 \mathrm{wt} \%$ relative to the water. We varied the ratio between the two monomers from $10 / 0$ to $0 / 10$. As shown here, both the number and weight average molecular weights of PBMA particles were found to be the highest followed by those of PS particles. Since the propagation rate of the styrene 


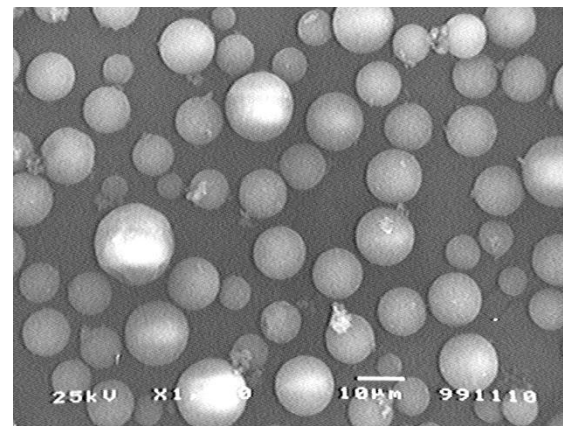

(a)

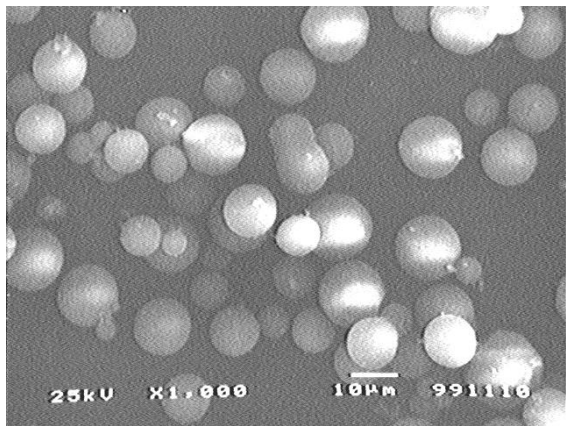

(b)

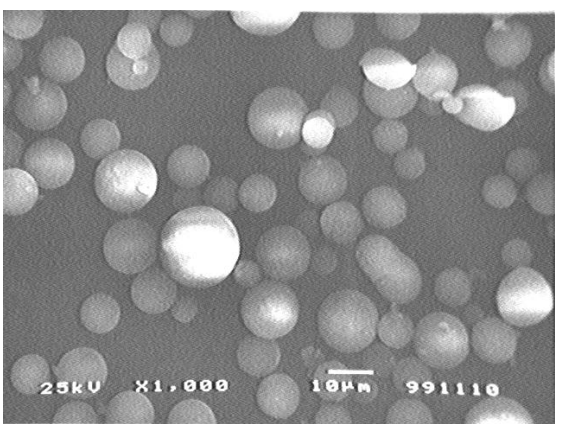

(c)

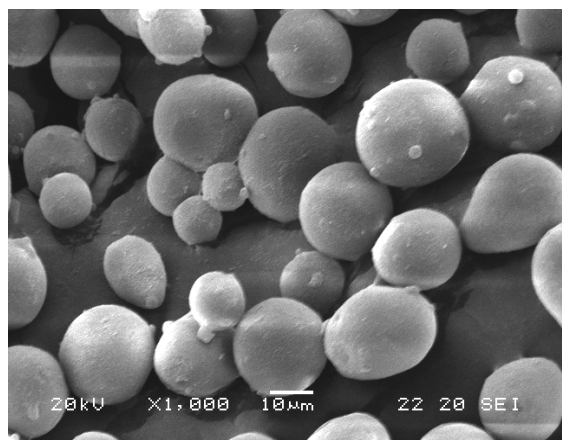

(d)

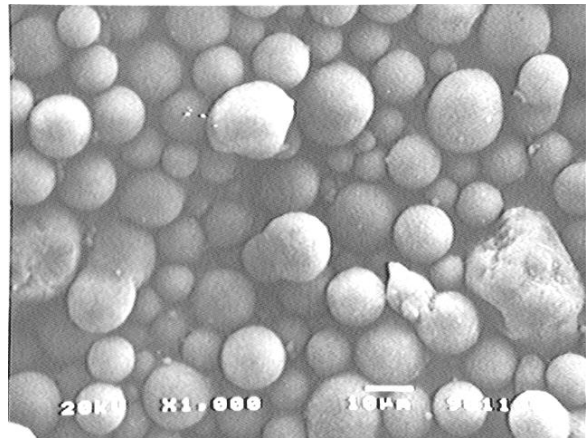

(e)

Figure 5. SEM photographs of copolymer particles composed of varying ratios between styrene and BMA in a suspension polymerization at $75{ }^{\circ} \mathrm{C}$ with $1.0 \mathrm{wt} \%$ of silica as a stabilizer and $1.0 \mathrm{wt} \% \mathrm{AIBN}$ as an initiator (X1,000): (a) SB11 $(1.07 / 13.1 / 20.1 \mu \mathrm{m})$, (b) SB02 (7.44/18.3/33.3 $\mu \mathrm{m})$, (c) SB13 (6.66/19.0/38.0 $\mu \mathrm{m})$, (d) SB14 $(11.4 / 24.9 / 42.2 \mu \mathrm{m}),(\mathrm{e})$ SB16 $(9.33 / 27.4 / 58.7 \mu \mathrm{m})$.

monomer $(72.51 / \mathrm{mol} \cdot \mathrm{sec})$ is lower than that of BMA (372 $1 / \mathrm{mol} \cdot \mathrm{sec})$ and the termination rate of the styrene monomer $\left(6.7 \times 10^{7} \mathrm{l} / \mathrm{mol} \cdot \mathrm{sec}\right)$ is higher than that of BMA $\left(2.9 \times 10^{7} \mathrm{l} / \mathrm{mol}\right.$ $\cdot \mathrm{sec}){ }^{30}$ the molecular weights of PS will be lower than those of PBMA. The reactivity ratio of styrene and BMA in copolymerication are 0.52 and 0.47 , respectively. The similar reactivity of both monomers close to 0.5 indicates that both the styrene and BMA monomer tend to form an alternate copolymer before one monomer is depleted. On the other hand, differences in polarity and steric hindrance are likely to discourage accessibility of the two monomers towards each other. The reduction in collision frequency of the two monomers may have caused a decrease in both the number and weight average molecular weights, as shown in Table 2 (SB11, 12, 02 and 13). With an increasing proportion of the BMA monomer, however, an early depletion of the styrene monomer is speculated to enable the propagation of BMA chains, which will lead to a general increase in molecular weights (SB 14, 15 and 16). The tendency of molecular weight variation of copolymers composed of the styrene and BMA monomer is similar to what was reported in a bulk polymerization of styrene and BMA. ${ }^{31}$ Figure 5 shows variation of particle shape and size depending on the ratio between the styrene and BMA mono- mer, observed by scanning electron microscopy. Copolymer particles with a higher proportion of the styrene display a spherical shape (Figure 5(a), 5(b)), whereas copolymer particles containing $50 \mathrm{wt} \%$ of BMA start to display irregularity in particle shape (Figure 5(c)). A further increase in BMA concentration displays an increase in both irregularity and particle diameter (Figure 5(d), 5(e)). Since all the copoly(styrene/BMA) particles prepared by suspension polymerization with hydrophobic silica as a stabilizer display polydispersity in particle diameter, we measured particle size distribution for the five samples in Figure 5. The three numbers in the parenthesis of Fig. 5 represent $\mathrm{D}(\mathrm{V}, 0.1) \mu \mathrm{m}, \mathrm{D}(\mathrm{V}, 0.5) \mu \mathrm{m}$ and $\mathrm{D}(\mathrm{V}, 0.9) \mu \mathrm{m}$, respectively. As can be seen here, there are more larger particles forming with an increase in BMA concentration. A decrease in glass transition with an increase in the concentration of BMA (Table 2) are speculated to contribute to a large increase in particle diameter and irregularity in particle shape. The glass transition temperature was found to be a strong function of the ratio between the styrene and BMA monomer, as can be seen in Table 2. The variation was found to be in good agreement with the Fox equation.

Figure 6 shows the conversion against reaction time as a function of the initiator concentration. We varied the initiator 


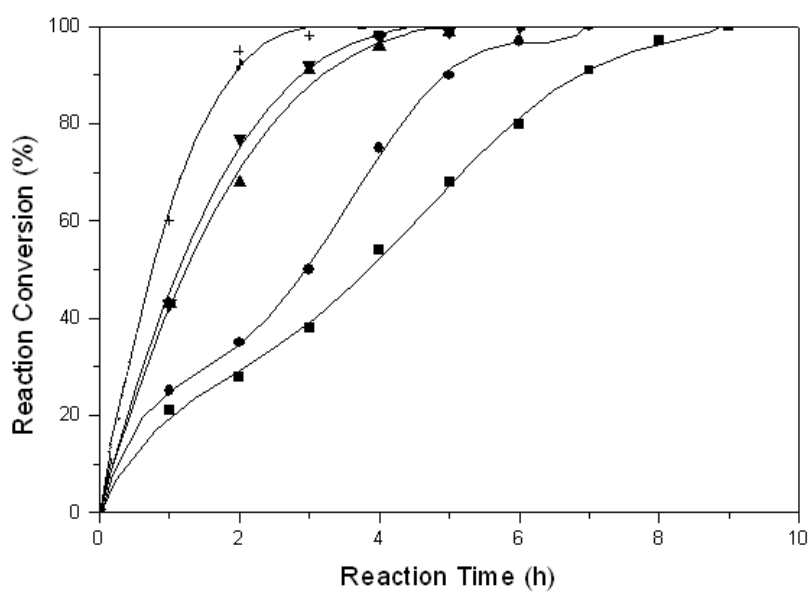

Figure 6. Conversion against reaction time for varying initiator concentrations relative to the monomer in a suspension copolymerization of styrene and BMA at $75{ }^{\circ} \mathrm{C}$ with $1.0 \mathrm{wt} \%$ hydrophobic silica as a stabilizer and AIBN as an initiator: 0.25 $\mathrm{wt} \%$ (SB21), $0.50 \mathrm{wt}^{\%}$ (SB22), $\boldsymbol{\Delta} 1.0 \mathrm{wt} \%(\mathrm{SB} 02) \boldsymbol{\nabla}$ $2.0 \mathrm{wt} \%(\mathrm{SB} 23),+5.0 \mathrm{wt} \%(\mathrm{SB} 24)$.

Table 3. Effect of Initiator Concentration on the Molecular Weights of Copoly (styrene/BMA) particles with the ratio of $7 / 3$ prepared at $75{ }^{\circ} \mathrm{C}$ with $1.0 \mathrm{wt} \%$ Silica as a Stabilizer by Suspension Polymerization

\begin{tabular}{c|c|c|c|c}
\hline ID & Initiator $(\mathrm{g})$ & Initiator $(\mathrm{wt} \%)$ & $\mathrm{Mn}(\mathrm{g} / \mathrm{mol})$ & $\mathrm{Mw}(\mathrm{g} / \mathrm{mol})$ \\
\hline SB21 & 0.38 & 0.25 & 129,000 & 378,800 \\
\hline SB22 & 0.75 & 0.50 & 72,000 & 240,000 \\
\hline SB02 & 1.50 & 1.0 & 44,800 & 136,800 \\
\hline SB23 & 3.00 & 2.0 & 27,800 & 74,800 \\
\hline SB24 & 7.50 & 5.0 & 17,900 & 46,700 \\
\hline
\end{tabular}

Table 4. Effect of Reaction Temperature on the Molecular Weights of Copoly (styrene/BMA) particles with the ratio of $7 / 3$ prepared at $75{ }^{\circ} \mathrm{C}$ with $1.0 \mathrm{wt} \%$ Silica as a Stabilizer and $1.0 \mathrm{wt} \% \mathrm{AIBN}$ as an Initiator by Suspension Polymerization

\begin{tabular}{c|c|c|c}
\hline ID & Temp $\left({ }^{\circ} \mathrm{C}\right)$ & $\mathrm{Mn}(\mathrm{g} / \mathrm{mol})$ & $\mathrm{Mw}(\mathrm{g} / \mathrm{mol})$ \\
\hline SB31 & 65 & 58,900 & 153,600 \\
\hline SB02 & 75 & 44,800 & 136,800 \\
\hline SB32 & 85 & 39,200 & 106,100 \\
\hline SB33 & 95 & 28,000 & 69,000 \\
\hline
\end{tabular}

concentration from $0.25 \mathrm{wt} \%$ to $5.0 \mathrm{wt} \%$ relative to the monomer. The stabilizer concentration was fixed at $1.0 \mathrm{wt} \%$ relative to the water with the ratio between the styrene and BMA monomers to be $7 / 3$. Reaction temperature was maintained at $75{ }^{\circ} \mathrm{C}$. As can be seen here, reaction rate increases rapidly at the beginning of the reaction, typical for suspension polymerization. It takes longer for reaction to reach completion with a decrease in the initiator concentration. When the initiator concentration was selected to be $0.25 \mathrm{wt} \%$ relative to the monomer, the reaction took 9 hours before reaching completion. Variation in molecular weights as a function of the initiator concentration is tabulated in Table 3. As seen here, both the number and weight average molecular weights of copolymer beads composed of the styrene and BMA monomers with the ratio of $7 / 3$ prepared by suspension polymerization using hydrophobic silica as a stabilizer decrease with an increase in the initiator concentration. In theory, the number average molecular weight is proportional to the reciprocal of the square root of the initiator concentration. ${ }^{30}$ When we doubled the initiator concentration in a suspension polymerization of styrene/BMA with hydrophobic silica as a stabilizer and AIBN as an initiator, the ratio of the number average molecular weights was found to be 0.56 (SB22/SB21), 0.61 (SB02/SB22) and 0.63 (SB23/SB02) in comparison to the theoretical value of 0.71 . When we increased the initiator concentration by 2.5 times, the ratio of the number average molecular weights was found to be 0.64 (SB24/SB23) in comparison to the theoretical value of 0.63 . Despite a slight discrepancy at low initiator concentrations, it is conceivable that the variation of the number average molecular weights is, in general, found to be in close agreement with the theory. ${ }^{29}$

Table 4 shows the variation of molecular weight and particle size depending on the polymerization reaction temperature. We selected $65,75,85$ and $95^{\circ} \mathrm{C}$. The ratio between the monomer and water was maintained at 1 to 3 . We found that reaction rate increased with increasing polymerization reaction temperature (Figure 7). At $65^{\circ} \mathrm{C}$, the reaction reached completion

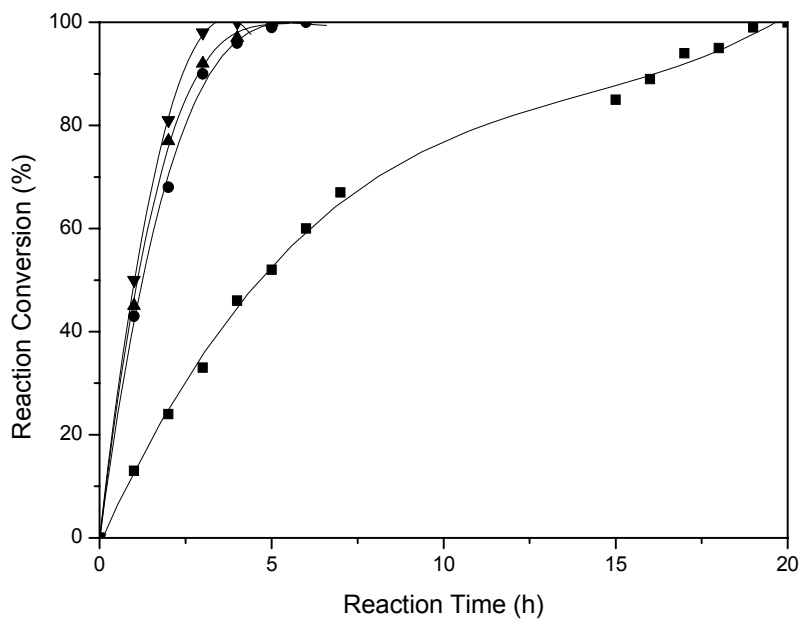

Figure 7. Conversion against reaction time at varying reaction temperatures in a suspension copolymerization of styrene and BMA with $1.0 \mathrm{wt} \%$ silica as a stabilizer and $3.0 \mathrm{wt} \%$ AIBN as an initiator: $65{ }^{\circ} \mathrm{C}$ (SB31), $75{ }^{\circ} \mathrm{C}$ (SB02), $\boldsymbol{\Delta} 85$ ${ }^{\circ} \mathrm{C}$ (SB32), $\boldsymbol{\nabla} 95{ }^{\circ} \mathrm{C}$ (SB33). 


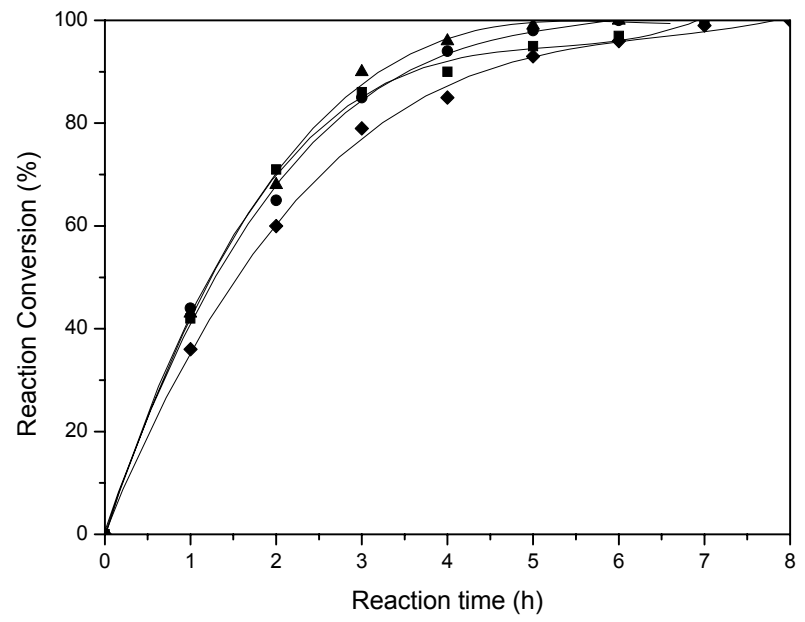

Figure 8. Reaction conversion against reaction time for varying carbon black concentrations in a suspension copolymerization of styrene and BMA with $1.0 \mathrm{wt} \%$ silica as a stabilizer and $1.0 \mathrm{wt} \%$ AIBN as an initiator: $\Delta 0 \mathrm{wt} \%$ (SB02), $1.0 \mathrm{wt} \%$, $3.0 \mathrm{wt} \%$, $5.0 \mathrm{wt} \%$.

nearly twenty hours after the reaction started. At the reaction temperatures of 75,85 and $95^{\circ} \mathrm{C}$, it took six, five and four hours, respectively, for the reaction to reach completion. The number and weight average molecular weights displayed a decrease with increasing polymerization reaction temperature, as can be seen in Table 4 . In theory, the number average molecular weight is proportional to the exponential of $(\mathrm{Ei} / 2+\mathrm{Et} /$ 2-Ep)/RT, where Ei, Ep and Et represent the activation energies for initiation, propagation and termination, respectively. ${ }^{32}$ When we calculated the ratio between the measured number average molecular weights and the expected number average molecular weights based on the theoretical equation, we found that the ratio was between 1.05 and 1.31.

We made an attempt to synthesize copolymer particles containing carbon black in the range of 1 to $5 \mathrm{wt} \%$ relative to the monomer. We selected the ratio between the two monomers to be $7 / 3$ (styrene/BMA). We ran a suspension copolymerization at $75^{\circ} \mathrm{C}$ with the initiator concentration of $1.0 \mathrm{wt} \%$ relative to the monomer and the stabilizer concentration of $1.0 \mathrm{wt} \%$ relative to the water. For the dispersion of carbon black particles, we employed the same mixing condition we previously reported, i.e., at $50 \mathrm{rpm}$ for 24 hours with a ballmill. $^{26}$ After preparing a liquid mixture composed of the two monomers, initiator and carbon black particles by ballmilling, we added it to a 1-liter kettle reactor in which the silica stabilizer was dispersed. We, then, homogenized the entire composite liquid mixture at 5,000 rpm for 10 minutes to create preliminary particles. Figure 8 displays reaction conversion against reaction time for a suspension copolymerization of styrene and BMA containing various concentrations of carbon

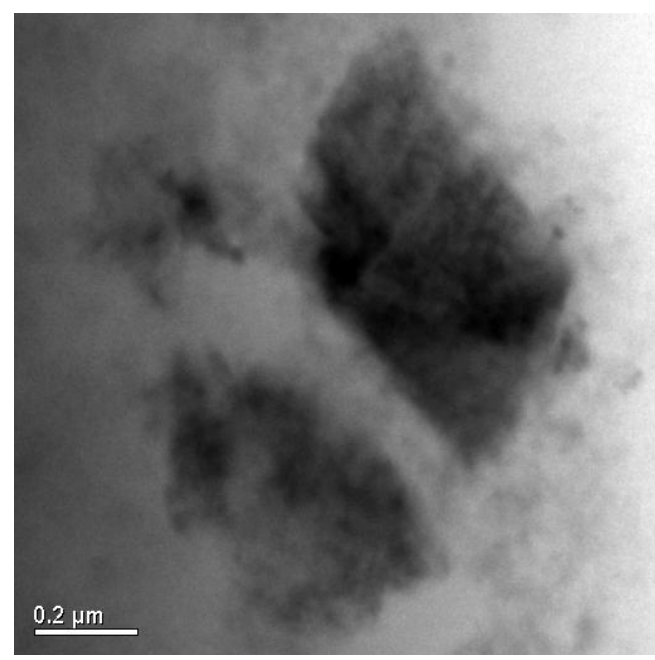

(a)

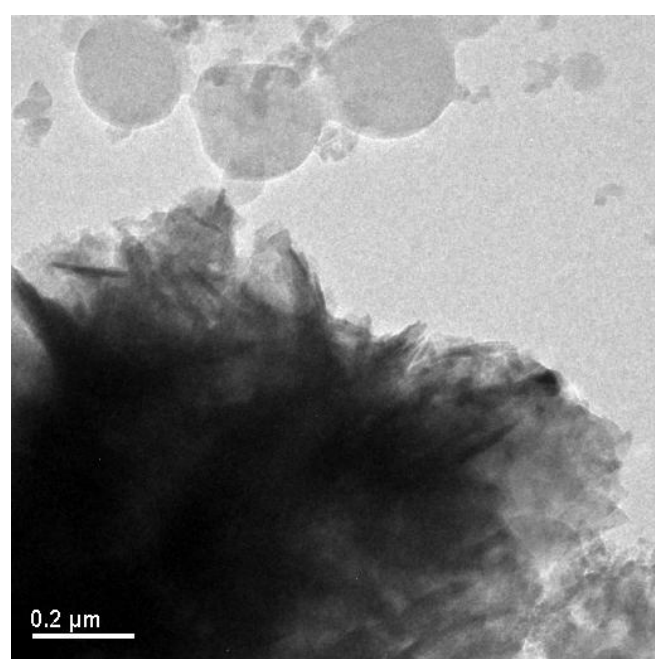

(b)

Figure 9. TEM images of copoly(styrene/BMA) particles containing 1 and $5 \mathrm{wt} \%$ carbon black prepared by suspension copolymerization of styrene and BMA with $1.0 \mathrm{wt} \%$ silica as a stabilizer and $1.0 \mathrm{wt} \%$ AIBN as an initiator: (a) $1.0 \mathrm{wt} \%$ $\mathrm{CB}$, (b) $5.0 \mathrm{wt} \% \mathrm{CB}$.

black. As can be seen here, an increase in carbon black concentration prolongs reaction time to reach completion. It is conceivable that carbon black hinders radical diffusion and, as a result, slows the reaction rate. Carbon black is known to be a radical scavenger, ${ }^{33}$ which contributes to a reduction in radical concentration. Figure 9 shows images of TEM for copoly(styrene/BMA) composites particles containing 1 and $5 \mathrm{wt} \%$ carbon black. As can be seen here, composite particles with higher CB content show a higher concentration of carbon black over a larger area. 


\section{Conclusion}

We found that the hydrophobic silica R972 were dispersed into water at pH10 and could be used as a stabilizer in a suspension copolymerization of styrene and BMA. Stabilizer concentration was found to have a significant effect not only on the stability but the diameter of preliminary particles. Variation of diameters and molecular weights of the copolymer particles depending on the amount of stabilizer is identical to what was reported in a suspension polymerization of styrene and that of BMA.

An increase in the polymerization reaction temperature and initiator concentration exhibited a reduction in both the number and weight average molecular weights. The extent of molecular weight variation as a function of the initiator concentration and reaction temperature was found to be in good agreement with the theoretical equation. Particle diameter was found to be nearly independent of the initiator concentration and reaction temperature.

Incorporation of carbon black required ballmilling to enhance dispersion of filler particles in the monomer phase and to contributing to reducing particle size. With an increase in concentrations of carbon black, reaction took longer to reach completion. We confirmed the presence of carbon black particles by TEM.

\section{References}

1. Y. Jin, Y. Zhu, X. Yang, H. Jiang, and C. Li, "In Situ Synthesis of sulfide-coated Polystyrene Composites for the Fabrication of Photonic Crystals", J. Colloid Inter. Sci., 301, 130 (2006).

2. S. Zhang, X. W. Zhao, H. Xu, R. Zhu, and Z. Z. Gu, "Fabrication of Photonic Crystals with Nigrosine-doped Poly (MMA-co-DVB-co-MAA) Particles", J. Colloid Inter Sci., 316, 168 (2006).

3. A. M. Hillery, "Microparticulate Delivery Systems: Potential Drug/Vaccine Carriers via Mucosal Routes", Pharm. Sci. Tech. Today, 1-2, 69 (1998).

4. J. Liang, F. Svec, and J. M. Frechet, "Preparation and Functionalization of Reactive Monodisperse Macroporous Poly(chloromethylstyrene-co-styrene-co-divinylbenzene) Beads by a Staged Templated Suspension Polymerization", J. Polym. Sci.: Part A: Polym. Chem., 33, 2639 (1995).

5. A. N. Shipway, "Colloids and Colloids Assemblies - Synthesis, Modification, Organization and Utilization of Colloid Particles Ed. F. Caruso", Chemphyschem-Weinheim, 5-11, 1805 (2004).

6. S. Omi, K. Fujiwara, M. Nagai, G. Ma, and A. Nakano, "Study of Particle Growth by Seed Emulsion Polymerization with Counter-charged Monomer and Initiator System", Colloids and Surfaces, 153, 165 (1999).

7. I. Noda, T. Kamoto, and M. Yamada, "Size-Controlling
Synthesis of Narrowly Distributed Particles of Methylsilsesquioxane Derivatives”, Chem. Mater., 12, 1708 (2000).

8. M. S. Kim, S. K. Kim, J. Y. Lee, S. H. Cho, K. Lee, J. Kim, and S. Lee, "Synthesis of Polystyrene Nanoparticles with Monodisperse Size Distribution and Positive Surface Charge Using Metal Stearates", Macromol. Res., 16-2, 178 (2008)

9. C. Ma, I. Taniguchi, M. Miyamoto, and Y. Kimura, "Formation of Stable Nanoparticles of Poly(phenyl/methylsilsesquioxane) in Aqueous Solution", Polymer J., 35-3, 270 (2003).

10. C. Ma and Y. Kimura, "Preparation of Nano-particles of Poly(phenylsilsesquioxane)s by Emulsion Polycondensation of Phenylsilanetriol Formed in Aqueous Solution", Polymer J., 34-9, 709 (2002).

11. J. Hearn, M. C. Wilkinson, A. R. Goodall and M. Chainey, "Kinetics of the Surfactant-Free Emulsion Polymerization of Styrene: The Post Nucleation Stage", J. Polym. Sci., 23, 1869 (1985).

12. Z. Song and G. W. Poehlein, "Kinetics of Emulsifier-Free Emulsion Polymerization of Styrene", J. Polym. Sci.: Polym. Chem., 28-9, 2359 (1990).

13. J. L. Guillaume, C. Pichot and J. Guillot, "Emulsifier-Free Emulsion Copolymerization of Styrene and Butyl Acrylate. I.* Kinetic Studies in the Absence of Sulfactant", J. Polym. Sci.: Polym. Chem., 28, 119 (1990).

14. K. J. O'Callaghan, A. J. Paine, and A. Rudin, "Mixed Initiator Approach to the Surfactant-Free Semicontinuous Emulsion Polymerization of Large MMA/BA Particles", J. Appl. Polym. Sci., 58, 2047 (1995).

15. T. Tranrisever, O. Okay, and C. Soenmezoglu, "Kinetics of Emulsifier-Free Emulsion Polymerization of MEthyl Methacrylate", J. Appl. Polym. Sci., 61, 485 (1996).

16. Z. Xu, C. Yi, G. Lu, J. Zhang, and S. Cheng, "Styrene-Butyl Acrylate-N,N-Dimethyl N-Butyl N-Methacrylamidino Propyl Ammonium Bromide Emulsifier-free Emulsion Copolymierzation", Polym. Inter., 44, 149 (1997).

17. R. Olayo, E. Garcia, Garcia-Corichi, L. Sanchez-vazquez, and J. Alvarez, "Poly(vinyl alcohol) as a Stabilizer in the Suspension Polymerizaton of Styrene: The Effect of the Molecular Weight", J. Appl. Sci., 67, 71 (1998).

18. G. Odian, "Principles of Polymerization, 4th ed.", p. 298, Wiley Interscience, New York (2004).

19. Y. Taguchi, K. Hosogai, and M. Tanaka, "Effect of Dry Powder Preparation Conditions on Polymer Particles in Suspension Polymerization", J. Nihon Chem. Eng., 25-5, 758 (1999).

20. R. Murakami, H. Hachisako, K. Yamada, and Y. Motozato, "Preparation of Micron-Sized Poly(vinyl acetate) Particles by Suspension Polymerization Using Poly(vinyl alcohol) -Borate Complex Stabilizer", Polymer J., 25-2, 205 (1993).

21. S. Shaghaghi and A. R. Mahdavian, "The Effect of Sodium Dodecyl Benzene Sulfonate on Particle Size in Suspension Polymerization of Styrene: A New Investigation", Polym. 
Plas. Tech. Eng, 45, 109 (2006).

22. Y. M. Abu-Ayana and R. M. Mohsen, "Study of Some Variables Affecting Particle Size Distribution of Suspension Polymerization of Methyl Methacrylate", Polym. Plas. Tech. Eng., 44, 1515 (2005).

23. S. S. Kim, T. S. Park, B. C. Shin, and Y. B. Kim, "Polymethyl methacrylate/montmorillonite nanocomposite beads through a suspension polymerization-derived process", J. Appl. Polym. Sci., 97, 2340 (2005).

24. N. Sawatari, M. Fukuda, Y. Taguchi, and M. Tanaka, "The Effect of Surface Treatment of Magnetite Powder on a Structure of Composite Particles Prepared by Suspension Polymerization", J. Chem. Eng. Japan, 37-6, 731 (2004).

25. M. Park, Polymer(Korea), "Preparation of Polystyrene Beads by Suspension Polymerization with Hydrophobic Silica as a Stabilizer in Aqueous Solution", 30-6, 498 (2006).

26. J. Moon and M. Park, Polymer (Korea), "Suspension Polymerization with Hydrophobic Silica as a Stabilizer III. Poly(butyl methacrylate) Composite Particles Containing Carbon Black",
33-5, 477 (2009).

27. Nippon Aerosil Co., LtD., "Introduction of Aerosil Products" (2005).

28. R. K. Iler, "The Chemistry of Silica", p. 60-61, John Wiley \& Sons, New York (1978).

29. G. Odian, "Principles of Polymerization, 4th ed.", p. 236, Wiley Interscience, New York (2004).

30. J. Brandrup and E. Immergut, "Polymer Handbook, 3rd ed.", p. $70 \& 75$, Wiley Interscience, New York (1989).

31. D. Li, N. Li, and R. A. Hutchinson, "High-Temperature Free Radical Copolymerization of Styrene and Btuyl Methacrylate with Depropagation and Penultimate Kinetic Effects", Macrolmolecules., 39-13, 4366 (2006).

32. G. Odian, "Principles of Polymerization, 4th ed.", p. 274, Wiley Interscience, New York (2004).

33. H. Mark, N. Bikales, C. Overberger, and G. Menges, "Encyclopedia of Polym. Sci. \& Eng, 2nd ed., Vol. 15", page 560 (1989). 